\title{
A Brief Review on Biomedical Applications of Hydroxyapatite Use as Fillers in Polymer
}

\author{
Alhussein Arkan Majhool, ${ }^{1}$ Ismail Zainol ${ }^{1}$, Che Nor Aiza Jaafar ${ }^{2}$, Alsailawi H. A. ${ }^{3}$, Mohammad Zorah Hassan ${ }^{1}$, \\ Mustafa Mudhafar ${ }^{1}$, Ali Arkan Majhool ${ }^{3}$ and Abbas Asaad ${ }^{3}$ \\ 1. Department of Chemistry, Faculty of Science and Mathematics, Sultan Idris Education University, Tanjong Malim 35900, Perak \\ Darul Ridzuan, Malaysia \\ 2. Department of Mechanical and Manufacturing Engineering, Faculty of Engineering, Universiti Putra Malaysia, Serdang 43400, \\ Selangor, Malaysia \\ 3. Department of Biology, Faculty of Science and Mathematics, Sultan Idris Education University, Tanjong Malim 35900, Perak \\ Darul Ridzuan, Malaysia
}

\begin{abstract}
Preparation of hydroxyapatite (HA) through natural sources, such as fish scales or synthetic HA produced from the chemical reaction has been widely used as biomedical materials because HA is bioactive, non-toxic and osteoconductive with a crystallographic structure almost similar to that of the bone mineral. In addition, HAwith particle size $<10$ microns is classified as common inorganic filler used to improve the mechanical properties and biocompatibility of polymer composites. The purpose of this review is to collect information related to HA, and to provide readers with information about synthesis methods, advantages of hydroxyapatite as biomaterial,biomedical applications of polymer/HA composites.
\end{abstract}

Keywords: Biomedical, hydroxyapatite, polymer, fillers.

\section{Introduction}

\subsection{Hydroxyapatite (HA)}

HA is a type of calcium phosphate with a chemical formula of $\mathrm{Ca}_{10}\left(\mathrm{PO}_{4}\right)_{6}(\mathrm{OH})_{2}$ [1-4]. Pure $\mathrm{HA}$ is a stoichiometric apatite phase with a $\mathrm{Ca} / \mathrm{P}$ molar ratio of 1.67 , the most stable calcium phosphate salt at normal temperatures and $\mathrm{pH}$ between 4 and 12 [5]. The crystal structure of HA most frequently encountered is hexagonal, having the $\mathrm{P}_{3} / \mathrm{m}$ space group symmetry with lattice parameters of $a=b=9.432, c=6.881 \mathrm{~A}^{\circ}$, and $\nabla=120^{\circ}$. Many studies have drawn great interest of hydroxyapatite because HA is widely used as biomedical material $[6,7]$. HA is a ceramic material with osteoconductive and biocompatibility properties similar to those of bones' mineral phase [4, 8-12]. HA can also enhance the growth of bones and assimilate

Corresponding author: Alhussein Arkan Majhool, $\mathrm{PhD}$, Department of Chemistry, Faculty of Science and Mathematics, Sultan Idris Education University. with the surrounding bone tissues. It serves as a support and filler to the bones [13-16]. Given its incompetence properties, HA is a very promising biomaterial source [17-20]. In addition, hydroxyapatite (HAp) is also exploited as a model compound to mimic the biomineralization process $[21,22]$. However, HA with particle size $<10$ microns is classified as common inorganic filler used to improve the mechanical properties and biocompatibility of polymer composites [23-29], because of its excellent biocompatibility properties, non-toxic, non-immunog-enic and osteoconductive [23, 30-34]. It is similar to the silica powder used in polymer composites [35-38]. The human bone is a calcified tissue composed of $60 \%$ inorganic component (hydroxyapatite), 10\% water and $30 \%$ organic component (proteins) [39]. Technically, bone tissue has a nano-scaled classified structure composed of HA crystals within a matrix of collagen fibers and other proteins [40]. Fig. 1 displays biomedical applications of HA. 


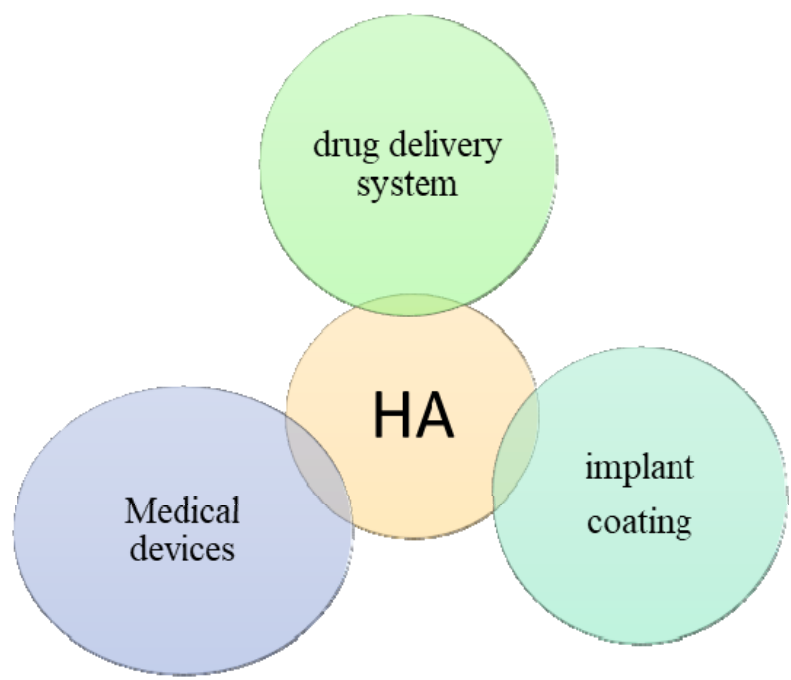

Fig. 1 Schematic illustration of biomedical applications of hydroxyapatite.

\subsection{Synthesis of $H A$}

HA can be synthesised as new biomaterials from different sources. Commercially available HA is chemically synthesised through chemical reactions, such as chemical precipitation [41-45]. Several techniques for HA synthesis have been established, such as sol-ge [42], wet chemical precipitation [46], sonochemical [47] and microwave [48]. Wang et al. [32] synthesised nanocrystalline HAp through precipitation reaction between calcium nitrate and diammonium phosphate, and the $\mathrm{pH}$ was confirmed using ammonia, $\mathrm{NH}_{4} \mathrm{OH}$. At temperatures as low as $300^{\circ} \mathrm{C}$, combustion occurs and the synthesised powder produces grains with sizes ranging from $50 \mathrm{~nm}$ to 100 $\mathrm{nm}$ [32]. In reference to Saeri et al. [49], the completion of precipitated $\mathrm{HA}$ at 850 and $12,000^{\circ} \mathrm{C}$ for $2 \mathrm{~h}$ may cause the reduction of water availability and increment of crystallinity. This phenomenon occurs when the suspension is left after dropping the acid solution [49].

Similarly, Sadat et al. [21] produced HA nanorods by using a simple hydrothermal method. An appropriate amount of ammonia and calcium nitrate solution was dissolved, and the molar ratio of $\mathrm{Ca} / \mathrm{P}$ was adjusted to 1.67 . At $200^{\circ} \mathrm{C}$, the HA precursor was hydrothermally treated for $6 \mathrm{~h}$. A similar method was also reported by Zhu et al. [33]. The outcome revealed that the synthesised HA nanorods contain high crystallinity with high aspect ratio. Kalita et al. [48] synthesised HAp at the lower end of the nanoregime by using microwave. Through this method, calcium nitrate tetrahydrate and sodium phosphate anhydrous were used as the starting materials to synthesise the powder. This method produces an average crystallite size of around $12 \mathrm{~nm}$ and highly crystalline nanopowder with sizes ranging from $5 \mathrm{~nm}$ to $30 \mathrm{~nm}$. Meanwhile, Yoshimura et al. [50] produced HA whiskers under hydrothermal conditions in the presence of disodium ethylenediaminotetra-acetic salt $\left(\mathrm{Na}_{2}\right.$ EDTA). The morphology of $\mathrm{HA}$ was significantly affected by the $\mathrm{pH}, \mathrm{Na}_{2}$ EDTA/Ca ratio and reaction temperature; HA microspheres with high crystallinity resulted from conditions with high $\mathrm{pH}$, high temperature and moderate retention time.

\subsection{Natural Hydroxyapatite}

Commercially available HA is chemically synthesised through chemical reactions, such as chemical precipitation $[45,51,52]$. However, in consideration of the high cost associated with chemicals used in the synthetic process, other natural sources were explored for the inexpensive production of HA. Biological sources, such as fish scales, fish 
bones, bovine bones, egg shells, snail shells, teeth and bones of pig, are among the major sources of natural HA [1, 2, 25, 53-59]. Fish scales contain abundant valuable organic and inorganic components, mainly collagen and HA [60]. HA from biological sources was prepared because it is biologically safe and economical. Several methods, including alkaline digestion, enzymatic and direct burning method, have been developed to extract HA from fish scales. Direct burning is an easy and cheap way of obtaining natural HA. Fish scales are burned at high temperature to remove organic component, and HA is retained as ash [53, 56, 57, 61]. Rosen et al. [62] studied the characteristics of HA from processed bone and found that the bone HA exhibits significant differences in crystal morphology compared with synthetic HA.

\section{Advantages of Hydroxyapatite as a Biomaterial}

The new rage in biomaterials research focused on nanocrystalline calcium phosphate-based bio ceramics. In nanobiotechnology, many researchers studied various methods to overcome the limitations of calcium phosphate and to fabricate nanostructured scaffolds to mimic the dimensional and structural details of natural bone. Calcium phosphate-based materials are ideal for bone grafts in hard tissue engineering because of their superior bioactivity and biocompatibility. Nevertheless, bioceramics have poor mechanical performance, which limits their applications in load bearing. The recent trend in bio ceramic research is mainly concentrated on bioactive and bioresorbable ceramics, i.e., HA, tricalcium phosphates and biphasic calcium phosphates, and bioactive glasses because of their superior biological properties over other materials [51, 57, 60, 63-66].

Nano-HA bioceramics have different applications, including bone tissue engineering, bone void fillers for orthopaedic, traumatology, spine, maxillofacial and dental surgery, orthopaedic and dental implant coating, restoration of periodontal defects, edentulous ridge augmentation, endodontic treatment (e.g., pulp capping, repair of mechanical furcation perforations and apical barrier formation), fillers for reinforcing restorative glass ionomer cement, desensitizing agent in post teeth bleaching, remineralising agent in toothpastes, early carious lesions treatment and drug and gene delivery [56, 61, 67-69]. The bone mineral consists of small HA crystals in the nano-regime. Nanocrystalline HA improves densification and sinter ability due to higher surface area, which improves the fracture toughness and other mechanical properties. HA has better bioactivity than other orthopaedic and dental implant materials [70]. It has many valuable properties that may remedy or reduce some undesired outcomes associated with metallic implants. HA is neither toxic to the body tissue nor targeted by the immune system as foreign body because it is a part of bone and teeth. Titanium and stainless steel implants are often covered with HA coatings to trick the body and reduce the implant rejection rate. HA can also be used in bone voids or defects. HA in the form of powders, blocks or beads is placed in the affected areas of bone. Given its bioactivity, HA encourages the bone to grow and restore the defects. This process can be an alternative to allogeneic and xenogeneic bone grafts. In addition, the use of HA shortens healing time [69, 71]. Synthetic nano-hydroxyapatite mimics the size of natural dentinal HA or enamel apatite. Experimental results have demonstrated the advantages of nano-HA in enamel repair [1, 69]. Thus, HA has been incorporated in toothpastes and mouth-rinsing solutions to promote the restoration of demineralised enamel or dentin surfaces by depositing HA nanoparticles in the defects $[11,72]$.

\section{Biomedical Applications of Polymer/HA Composites}

Nowadays, advances in medical science prolong the life span of a human and improve their standard of living. In the 1960s, the life expectancy at birth was about 69 years, but this was prolonged to 80 years in 
2010. This expectancy corresponds to the increase rate of life probability to 2.2 years per decade; this increase in life expectancy can be ascribed to the advances in medical science that addressed more illnesses and its associated diseases with old age, including wear on bodily tissues, especially long bones. Human bones, which are composed of calcium and type I collagen, produce both white and red blood cells and provide structural sustenance for the body. The bone structure comprises inorganic mineral calcium phosphate in calcium HA (a type of bone mineral for bone rigidity) and collagen, which is an elastic protein that helps improve fracture resistance [73].

However, tissue deterioration gradually occurs with age and contributes to the requirement of spare parts for the body. Trauma, desorption and pathology contribute to the fracture of bone tissue [74]. As age increases, the total calcium pool of the bone and bone density decreases [75]. The decrease in bone density may be due to less growth of bone, which then becomes less productive in engaging new bones, and progressively slows repairing mechanism of micro-fractures. These symptoms are more severe in women than in men because of the hormonal changes during the menopausal phase $[12,76]$. The elderly are prone to hip fracture or collapsed vertebrae and spinal problems because of the weak bone strength due to low bone density. Nickel, cobalt, molybdenum, chromium, zirconium and titanium alloys are orthopaedic implants, whereas stainless steel is used to fix the orthopaedic devices, such as screw plates [77]. According to Teoand Schalock (2016) [78], metal allergy occurs due to complication after joint replacement. Since the discovery of this phenomenon, the number of awareness and reported incidence has increased. Although the connection between metal implant failure and allergy is well documented and reported, the relationship between the two is still poorly understood and remains relatively unpredictable and highly debated.

HA is superior to other natural and synthetic materials with similar chemical compositions. The strong mechanical support is due to the unique structure of bone tissue in the body. In the human body, collagen is a type of protein with a triple helix structure [40]. Understanding the natural structure, composition and formation of bone tissue as well as new fabrication techniques is important in the development of new materials and improvement of current technologies. For instance, the degradation of bone tissue, especially in certain joints, such as the knee or the hip, results in the need to replace them with orthopaedic implants $[12$, 31, 56, 79]. Biocompatible and bio-stable polymers comprise few polymers that are potential matrices of bone analogues. These polymers are poly(methyl methacrylate), polyethylene (PE), polypropylene (PP), polyurethane, polytetrafluoroethylene, poly(vinyl chloride), polyamides, polycarbonate, poly(ethylene terephthalate), polyetheretherketone, polysiloxanes, epoxy resin [25, 80-84]. Biodegradable polymers have received considerable attention in the field of tissue engineering. These main class polymers comprise bioresorbable compounds known as alpha-polyesters or poly(alpha-hydroxy) acids [85], and poly (acrylonitrile-co-butadiene-co-styrene) (ABS) [86]. Many studies reported that polymers modified with HA filler improve the mechanical properties, such as tensile strength, flexural strength, impact energy and hardness, as well as biocompatibility of composites [23, 27, 87-90]. This finding can be ascribed to the excellent biocompatibility of HA [91].

Meanwhile, Scalera et al. [26] prepared epoxy/HA suspensions for stereo lithography to be applied to bone tissue engineering. The prepared epoxy/HA exhibits good mechanical properties. Similarly, Oladele et al. [25] prepared epoxy/HA composites and found that the composites display optimum mechanical properties, including flexural strength, tensile strength, impact strength and hardness. These mechanical properties of epoxy/HA composites render them structurally suitable for biomedical applications. Monmaturapoj et al. [27] prepared poly(lactic acid)/HA composites and found 
that the composites display good mechanical properties and are suitable for biomedical applications. In addition, Alhussein et al. in 2019 studied the improved mechanical properties and biocompatibility of epoxy resin through addition of fish scales hydroxyapatite powder (FsHAp). They found the highest flexural strength of epoxy/nHAp composite was recorded when the nHAp filler was $10 \mathrm{wt} \%$ which is $77 \%$ increment as compared to epoxy alone. The impact strength was increased up to twofold as compared to neat epoxy.

\section{Conclusions}

Due to the high cost associated with chemicals used in the synthetic HA process, other natural sources were explored for the inexpensive production of HA such as fish scales and fish bones. HA is a biocompatible and bioactive material while HA with particle size below $10 \mathrm{~m}$ is classified as fillers in polymer. The mechanical properties and biocompatibility of polymers were improved through addition hydroxyapatite as fillers.

\section{References}

[1] Mondal, S., Bardhan, R., Mondal, B., Dey, A., Mukhopadhyay, S. S., Roy, S., Guha, R. and Roy, K. 2012. "Synthesis, Characterization and in vitro Cytotoxicity Assessment of Hydroxyapatite from Different Bioresources for Tissue.” Bulletin of Materials Science 35 (4): 683-91.

[2] Fara, A. N. K. A., and Abdullah, H. Z. 2015. "Characterization of Derived Natural Hydroxyapatite (HAp) Obtained from Different Types of Tilapia Fish Bones andScales." AIP Conf. Proc. 1669 (1).

[3] Mondal, S., Mondal, B., Dey, A., and Mukhopadhyay, S. S. 2012. "Studies on Processing and Characterization of Hydroxyapatite Biomaterials from Different Bio Wastes." J. Miner. Mater. Charact. Eng. 11 (1): 55-67.

[4] Wibisono, Y.2018. "Communication Synthesis and Sinterability of Hydroxyapatite from Fishery By-Products." J. Korean Ceram. Soc.55 (6): 6-9.

[5] Koutsopoulos, S. 2002. "Synthesis and Characterization of Hydroxyapatite Crystals: A Review Study on the AnalyticalMethods." Wiley Period. (December 2001): 31-4.

[6] Dorozhkin, S. V. 2009. "Nanodimensional and Nanocrystalline Apatites and Other Calcium Orthophosphates in Biomedical Engineering, Biology and Medicine." Materials (Basel): 1975-2045.
[7] Xia, L., Lin, K., Jiang, X., Xu, Y., Zhang, M.,Chang, J., and Zhang, Z. 2013. "Enhanced Osteogenesis through Nano-structured Surface Design of Macroporous Hydroxyapatite Bioceramic Scaffolds via Activation of ERK and p38 MAPK Signaling Pathways.” Mater. Chem. B, No. 207890.

[8] Mondal, S., Mahata, S., Kundu, S., and Mondal, B. 2010. "Processing of Natural Resourced Hydroxyapatite Ceramics from Fish Scale." Advances in Applied Ceramics 109 (4): 234-9.

[9] Gao, C., Zhao, K., Lin, L., Wang, J., Liu, Y., and Zhu, P. 2019. "Preparation and Characterization of Biomimetic Hydroxyapatite Nanocrystals by Using Partially Hydrolyzed Keratin as Template Agent." Nanomaterials 9 (2).

[10] Pon-on, W., Suntornsaratoon, P., Charoenphandhu, N., and Thongbunchoo, J. 2016. "Hydroxyapatite from Fish Scale for Potential Use as Bone Scaffold or Regenerative Material." Mater. Sci. Eng. C62: 183-9.

[11] Gomes, D. S., Santos, A. M. C., Neves, G. A., Menezes, R. R., Grande,C., and Grande, C. 2019. "A Brief Review on Hydroxyapatite Production and Use in Biomedicine." Cerâmica 65: 282-302.

[12] Lin, K., and Chang, J. 2015. "Structure and Properties of Hydroxyapatite for Biomedical Applications." Elsevier Ltd.4214 (8).

[13] Pu, N. A. S. M., Koshy, P., Abdullah, H. Z., Idris, M. I., and Lee,T. C. 2019. "Syntheses of Hydroxyapatite from Natural Sources." Heliyon 5 (5).

[14] Venkatesan, J., Lowe, B., Manivasagan, P., Kang, K. H., Chalisserry, E., Anil, S., Kim, D. and Kim, S. K. 2015. "Isolation and Characterization of Nano-Hydroxyapatite from Salmon Fish Bone." Materials (Basel)8 (8): 5426-39.

[15] Alsailawi, H. A., and Rosmilah, M. 2019. "Effects of Food Processing on the Stability and Quality of Shellfish Allergens." J. US-China Med. Sci.16: 149-63.

[16] Plowright, R., Belto, D. J., Kaplan, D. L., and Perry, C. C. 2017. "Quantifying the Efficiency of Hydroxyapatite Mineralising Peptides." Scientific Reports 7: 1-9.

[17] Gao, C., Peng, S., Feng, P., and Shuai, C. 2017. "Bone Biomaterials and Interactions with Stem Cells." Nat. Publ. Gr.5 (October): 1-33.

[18] Vieira, E. G., da Silva Vieira, T. W., da Silva, M. P., dos Santos, M. V. B., de Sousa Brito, C. A. R., de Sousa Bezerra, R. D., Fialho, A. C. V., Osajima, J. A. and da Silva Filho, E. C. 2017. "Tuned Hydroxyapatite Materials for Biomedical Tuned Hydroxyapatite Materials for Biomedical Applications Applications."

[19] Mederle, N. 2016. "Innovative Biomaterials Based on Collagen-Hydroxyapatite and Doxycycline for Bone Regeneration.” Adv. Mater. Sci. Eng. 2016 (360): 1-5. 
[20] Wahl, D. A., and Czernuszka, J. T. 2006. "Collagen-Hydroxyapatite Composites for Hard Tissue Repair.” Eur. Cells Mater.11: 43-56.

[21] Sadat-Shojai, M., Khorasani, M., Dinpanah-Khoshdargi, E., and Jamshidi, A. 2013. "Acta Biom Aterialia Synthesis Methods for Nanosized Hydroxyapatite in Diverse Structures." ACTA Biomater.9 (8): 7591-621.

[22] Li, L., Pan, H., Tao, J., Xu, X., Mao, C., and Tang, R. 2008. "Repair of Enamel by Using Hydroxyapatite Nanoparticles as the Building Blocks." J. Mater. Chem. 4079-84.

[23] Majhool, A. A., Ismail Zainol, M. M. J., Azziz, S. S. S. A., and Jaafar, C. N. A. 2019. "Mechanical Properties Improvement of Epoxy Composites by Natural Hydroxyapatite from Fish Scales as A Fillers.” Int. J. Res. Pharm. Sci.10 (2): 1424-9.

[24] Jaafar, C. N. A., Zainol, I. and Amin, M. M. 2017. "Fish Scales Hydroxyapatite as Potential Fillers in HDPE Composites for Bone Replacement Applications." Solid State Phenom. 264: 79-82.

[25] Oladele, I. O., Akinola, O. S., Agbabiaka, O. G., and Omotoyinbo, J. A. 2018. "Mathematical Model for the Prediction of Impact Energy of Organic Material Based Hydroxyapatite (HAp) Reinforced Epoxy Composites." Fibers Polym. 19 (2): 452-9.

[26] Scalera, F., Esposito Corcione, C., Montagna, F., Sannino, A., and Maffezzoli, A. 2014. "Development and Characterization of UV Curable Epoxy/Hydroxyapatite Suspensions for Stereolithography Applied to Bone Tissue Engineering." Ceram. Int. 40 (10): 15455-62.

[27] Monmaturapoj, N. 2017. "Properties of Poly(lactic acid)/Hydroxyapatite Composite through the Use of Epoxy Functional Compatibilizers for Biomedical Application.” J. Biomater. Appl. 32 (2): 175-90.

[28] Supova, M. 2009 "Problem of Hydroxyapatite Dispersion in Polymer Matrices: A Review." Springer Sci. Media1201-13.

[29] Lee, H., Kim, J. S. E., Choi, H. W., Kim, C. W., Kim, K. J., and Lee, S. C. 2007. "Polymer the Effect of Surface-Modified Nano-Hydroxyapatite on Biocompatibility of Poly(e-caprolactone )/Hydroxyapatite Nanocomposites.” Eur. Polym. J. 43: 1602-8.

[30] Miranda, M., Esteban-Tejeda, L., and Malpartida, F. 2010. "Silver-Hydroxyapatite Nanocomposites as Bactericidal And Fungicidal Materials." International Journal of Materials Research 101 (1):122-7.

[31] Sadat-Shojai, M., Atai, M., Nodehi, A., and Nasiri, L. 2010. "Hydroxyapatite Nanorods as Novel Fillers for Improving the Properties of Dental Adhesives: Synthesis and Application." Dent. Mater. 26 (5): 471-82.

[32] Wang, J., and Shaw, L. L. 2009. "Biomaterials Nanocrystalline Hydroxyapatite with Simultaneous
Enhancements in Hardness and Toughness." Biomaterials 30 (34): 6565-72.

[33] Zhu, Y., Xu, L., Liu, C., Zhang, C. and Wu, N. 2018. "Nucleation and Growth of Hydroxyapatite Nanocrystals by Hydrothermal Method Nucleation and Growth of Hydroxyapatite Nanocrystals by HydrothermalMethod." AIP Advances 8 (8).

[34] Sossa, P. A. F., Giraldo, B. S., Garcia, B. C. G., Parra, E. R. and Arango, P. J. A. 2018. "Comparative Study between Natural and Synthetic Hydroxyapatite: Structural, Morphological and Bioactivity Properties." Matéria (Rio J.) 23 (4).

[35] Series, C. 2018. "Effect of Silica Fillers on Mechanical Properties of Epoxy/Kenaf Composites Effect of Silica Fillers on Mechanical Properties of Epoxy/Kenaf Composites." J. Phys. Conf., 3-9.

[36] Ahmad, T., and Mamat, O. 2013. "Studying the Effects of Adding Silica Sand Nanoparticles on Epoxy Based Composites." Journal of Nanoparticles 2013.

[37] Liu, Y., Hsu, C., Wei, W., and Jeng, R. 2003. "Preparation and Thermal Properties of Epoxy-Silica Nanocomposites from Nanoscale Colloidal Silica." Polymer 44: 5159-67.

[38] Chen, L. 2012. "Enhanced Epoxy/Silica Composites Mechanical Properties by Introducing Graphene Oxide to the Interface." ACS Appl. Mater. Interface 4 (8): 4398-404.

[39] Abraham, A., Ajith, S. D., and Divya, K. S. S. 2014. "Management Chemical Synthesis of Bone-Like Hydroxyapatite from Cuttle." International Journal of Engineering Sciences 4 (1): 2-5.

[40] Olszta, M. J., Cheng, X., Jee, S. S., Kumar, R., Kim, Y. Y., Kaufman, M. J., Douglas, E. P. and Gower, L. B. 2007. "Bone Structure and Formation: A New Perspective." Materials Science and Engineering: R: Reports 58: 77-116.

[41] Cai, Y., Mei, D., Jiang, T., and Yao, J. 2010. "Synthesis of Oriented Hydroxyapatite Crystals: Effect of Reaction Conditions in the Presence or Absence of Silk Sericin." Mater. Lett. 64 (24): 2676-8.

[42] Chen, J., Wang, Y., Chen, X., Ren, L., Lai, C., He, W. and Zhang, Q. 2011. “A Simple Sol-Gel Technique for Synthesis of Nanostructured Hydroxyapatite, Tricalcium Phosphate and Biphasic Powders." Mater. Lett. 65 (12): 1923-6.

[43] Guo, X., Yan, H., Zhao, S., Zhang, L., Li, Y., and Liang, X. 2013. "Effect of Calcining Temperature on Particle Size of Hydroxyapatite Synthesized by Solid-State Reaction at Room Temperature." Adv. POWDER Technol.

[44] Taylor, P., Al Qasas, N. S., and Rohani, S. 2005. "Synthesis of Pure Hydroxyapatite and the Effect of Synthesis Conditions on its Yield, Crystallinity, Morphology and Mean Particle Size.” Separation Science 
and Technology 40 (15): 3187-224.

[45] Yelten-Yilmaz, A., and Yilmaz, S. 2018. "Wet Chemical Precipitation Synthesis of Hydroxyapatite (HA) Powders." Ceram. Int.

[46] Zhang, G., Chen, J., Yang, S., Yu, Q., Wang, Z., and Zhang, Q. 2011. "Preparation of Amino-Acid-Regulated Hydroxyapatite Particles by Hydrothermal Method." Mater. Lett. 65 (3): 572-4.

[47] Rouhani, P., Taghavinia, N., and Rouhani, S. 2010. "Ultrasonics Sonochemistry Rapid Growth of Hydroxyapatite Nanoparticles Using Ultrasonic Irradiation." Ultrason.-Sonochemistry 17 (5): 853-6.

[48] Kalita, S. J., and Verma, S. 2010. "Nanocrystalline Hydroxyapatite Bioceramic Using Microwave Radiation: Synthesis and Characterization." Mater. Sci. Eng. C 30 (2): 295-303.

[49] Saeri, M. R., Afshar, A., Ghorbani, M., Ehsani, N., and Sorrell, C. C. 2003. "The Wet Precipitation Process of Hydroxyapatite.” Materials Letters 57: 4064-9.

[50] Yoshimura, M. 1994. "Hydrothermal Synthesis of Biocompatible Whiskers." J. Mater. Sci. 29.

[51] Tao, J., Jiang, W., Pan, H., Xu, X., and Tang, R. K. 2007. "Preparation of Large-Sized Hydroxyapatite Single Crystals Using Homogeneous Releasing Controls." Journal of Crystal Growth308: 151-8.

[52] Ikoma, T., and Yamazaki, A. 1999. "Preparation and Structure Refinement of Monoclinic Hydroxyapatite." Journal of Solid State Chemistry 276: 3-4.

[53] Kamalanathan, P. 2006. "Development of Hydroxyapatite from Natural Fish Bone through Heat Treatment." Trends in Biomaterials and Artificial Organs 20 (1):20-3.

[54] Mahmud, M. H., Salam, K. A., Gafur, M. A., Rana, A. A., Qadir, M. R., Masum, S. M., Sarker, M. and Karim, M. M. 2015. "Chemical Characteristics of Hydroxyapatite from Oyster Shell by Thermo-Chemical Process." Int. J. Innov. Res. Sci. Eng. Technol.

[55] Granito, R. N., Renno, A. C. M., Yamamura, H., de Almeida, M. C., Ruiz, P. L. M. and Ribeiro, D. A. 2018. "Hydroxyapatite from Fish for Bone Tissue Engineering: A Promising Approach.” Int J Mol Cell Med.7 (2): 80-90.

[56] Bahrololoom, M. E., Javidi, S., Javadpour, M., and Ma, J. 2009. "Characterisation of Natural Hydroxyapatite Extracted from Bovine Cortical Bone Ash." Journal of Ceramic Processing Research10 (2): 129-38.

[57] Zainon, I., Alwi, N. M., Abidin, M. Z., Haniza, H. M. Z., Ahmad, M. S., and Ramli, A. 2012. "Physicochemical Properties of Hydroxyapatite Extracted from Fish Scales." Adv. Mater. Res. 545: 235-9.

[58] Adenan, N. H., Rahim, N. A., Zainol, I., and Jaafar, C. N. A. 2018. "Extraction of Nanohydroxyapatite from Waste Bovine Bone Using Alkaline Digestion Method." J. Phys. Conf. Ser. 1082 (1).
[59] Mondal, S., Hoang, G., Manivasagan, P., Moorthy, M. S., Kim, H. H., Phan, T. T. V. and Oh, J. 2019. "Comparative Characterization of Biogenic and Chemical Synthesized Hydroxyapatite Biomaterials for Potential Biomedical Application." Mater. Chem. Phys.

[60] Nath, N., and Krishna, P. 2013. "Extraction and Characterization of Biocompatible Hydroxyapatite from Fresh Water Fish Scales for Tissue Engineering Scaffold." Bioprocess Biosyst Eng. 37 (3): 433-40.

[61] Bano, N., Jikan, S. S., Basri, H., Adzila, S., Bakar, S. A., and Nuhu, A. H. 2017. "Natural Hydroxyapatite Extracted from Bovine Bone."Journal of Science and Technology 9 (2): 22-8.

[62] Rosen, V. B., Hobbs, L. W., and Spector, M. 2002. "The Ultrastructure of Anorganic Bovine Bone and Selected Synthetic Hyroxyapatites Used as Bone Graft Substitute Materials." Biomaterials 23: 921-8.

[63] Tan, D. X., Xu, B., Zhou, X., and Reiter, R. J. 2018. "Associated Health Consequences and Rejuvenation of the Pineal Gland."

[64] Shi, P., Liu, M., Fan, F., Yu, C., Lu, W., and Du, W. 2018. "Characterization and Biocompatibility with Osteoblasts of Natural Hydroxyapatite Originated from Fish Bone." Materials Science and Engineering: C90: 706-12.

[65] Zima, A. 2017. "Hydroxyapatite-Chitosan Based Bioactive Hybrid Biomaterials with Improved Mechanical Strength." Spectrochim. Acta Part A Mol. Biomol. Spectrosc. 193: 175-84.

[66] Kalita, S. J., Bhardwaj, A., and Bhatt, H. A. 2007. "Nanocrystalline Calcium Phosphate Ceramics in Biomedical Engineering." Materials Science and Engineering: C27: 441-9.

[67] Ramli, R. A., Adnan, R., Bakar, M. A., and Masudi, S. M. 2011. "Synthesis and Characterisation of Pure Nanoporous Hydroxyapatite." J. Phys. Sci. 22 (1): 25-37.

[68] Cardoso, G. B. C., Tondon, A., Maia, L. R. B., Cunha, M. R., Zavaglia, C. A. C., and Kaunas, R. R. 2019. "In Vivo Approach of Calcium Deficient Hydroxyapatite Filler as Bone Induction Factor.” Materials Science \& Engineering C99: 999-1006.

[69] Ebenezer, V., Balakrishnan, K., and Sargunar, R. B. 2015. "Nano Hdroxyapatite Particulate Graft in Immediate Implant Placement - A Review of 10 Cases." Biomedical \& Pharmacology Journal8: 421-4.

[70] Li, X. G., Ma, B. G., Xu, L., Hu, Z. W., and Wang, X. G. 2006. "Thermogravimetric Analysis of the Co-combustion of the Blends with High Ash Coal and Waste Tyres." Thermochimica Acta 441: 79-83.

[71] Monika, Š. 2015. "Substituted Hydroxyapatites for Biomedical Applications: A Review." Ceramics International 41: 9203-31.

[72] Sahu, S., and Mehra, D. 2012. "Characterization and 
Thermal Analysis of Hydroxyapatite Bioceramic Powder Synthesized by Sol-Gel Technique." International Journal of Advanced Scientific Research and Technology 3 (2).

[73] Poundarik, A. A., Wu, P., Evis, Z., and Sroga, G. E. 2015. "A Direct Role of Collagen Glycation in Bone Fracture." $J$. Mech. Behav. Biomed. Mater. 52: 120-30.

[74] Rabie, A. B. M., Wong, R. W. K., and Hägg, U. 2000."Composite Autogenous Bone and Demineralized BoneMatrices Used to Repair Defects in the Parietal Bone of Rabbits."Br J Oral Maxillofac Surg. 38 (5): 565-70.

[75] Gallagher, J. C., and Harsha, S. 2013. "Prevention and Treatment of Postmenopausal Osteoporosis." J. Steroid Biochem. Mol. Biol., 1-16.

[76] Szcze, A., Ho, L., and Chibowski, E. 2017. "Synthesis of Hydroxyapatite for Biomedical Applications." $A d v$. Colloid Interface Sci. 249 (April): 321-30.

[77] Cunningham, D. J., Deorio, J. K., Nunley, J. A., Easley, M. E., and Adams, S. B. 2019. "The Effect of Patient Characteristics on 1 to 2-Year and Minimum 5-Year Outcomes after Total Ankle Arthroplasty." J. Bone. Joint Surg. Am. 103: 199-208.

[78] Teo, W. Z. W., and Schalock, P. C. 2016. "Metal Hypersensitivity Reactions to Orthopedic Implants." Dermatol. Ther. (Heidelb) 7 (1): 53-64.

[79] Grande, C. J., Torres, F. G., Gomez, C. M. and Bañó, M. C., 2009. "Nanocomposites of bacterial cellulose/hydroxyapatite for biomedical applications." Acta Biomaterialia 5 (5): 1605-1615.

[80] Wijesinghe, W. P. S. L. 2014. "Overview to Hydroxyapatite Nanoparticles and Their Applications." Sciscitator 1: 29-30.

[81] Armentano, I., Dottori, M., Fortunati, E., Mattioli, S., and Kenny, J. M. 2010. "Biodegradable Polymer Matrix Nanocomposites for Tissue Engineering: A Review." Polym. Degrad. Stab. 95 (11): 2126-46.

[82] Roeder, R. K., Converse, G. L., Kane, R. J., and Yue, W. 2008. "Hydroxyapatite-Reinforced Polymer Biocomposites for Synthetic Bone Substitutes." JOM 60 (3): $38-45$.

[83] Tiankhoon, L., Hassan, N. H., Rahman, M. Y. A., Vedarajan, R., Matsumi, N., and Ahmad, A. 2015. "One-Pot Synthesis Nano-Hybrid
$\mathrm{ZrO}<\mathrm{inf}>2</$ inf $>-\mathrm{TiO}<$ inf $>2<$ inf $>\quad$ Fillers in $49 \%$ Poly(Methyl Methacrylate) Grafted Natural Rubber (MG49) Based Nano-Composite Polymer Electrolyte for Lithium Ion Battery Application.” Solid State Ionics 276: 72-9.

[84] Murugan, R., and Ramakrishna, S. 2004. "Coupling of Therapeutic Molecules Onto Surface Modified Coralline Hydroxyapatite." Biomaterials 25: 3073-80.

[85] Yu, N. Y. C., Schindeler, A., Little, D. G., and Ruys, A. J. 2010. "Review Biodegradable Poly(Alpha-Hydroxy Acid) Polymer Scaffolds for Bone Tissue Engineering." $J$ Biomed Mater Res B Appl Biomater 93 (1): 285-95.

[86] Abad, M. J., Barral, L., Cano, J., Lopez, J., Nogueira, P., Ramírez, C. and Torres, A. 2001. "Thermal Decomposition Behavior and the Mechanical Properties of An Epoxy/Cycloaliphatic Amine Resin with ABS." European Polymer Journal 37: 1613-23.

[87] Park, Y. K., and Cho, C. H. 2016. "Effects of Additives on the Mechanical and Thermal Properties of Epoxy-Based Nanocomposites Produced Using Sonication." Korean J. Chem. Eng. 33 (6): 1938-41.

[88] Provenzi, C., Leitune, V. C., Collares, F. M., Trommer, R., Bergmann, C. P., and Samuel, S. M. 2014. "Interface Evaluation of Experimental Dental Adhesives with Nanostructured Hydroxyapatite Incorporation." Appl. Adhes. Sci. 2 (1): 1-5.

[89] Tayton, E., Purcell, M., Aarvold, A., Smith, J. O., Briscoe, A., Kanczler, J. M., Shakesheff, K. M., Howdle, S. M., Dunlop, D. G. and Oreffo, R. O. C. 2013. "A Comparison of Polymer and Polymer-Hydroxyapatite Composite Tissue Engineered Scaffolds for Use in Bone Regeneration. An in Vitro and in Vivo Study.” J. Biomed. Mater. Res. A. 102 (8):2613-24.

[90] Zebarjad, S. M., Sajjadi, S. A., and Sdrabadi, T. E. 2011. "A Study on Mechanical Properties of PMMA/Hydroxyapatite Nanocomposite." Engineering 3 (8): 795-801.

[91] Cheng, Q., Li, J., Li, S., and Zhi, K. 2019. "Corrosion Resistance and Antibacterial Properties of Hydroxyapatite Coating Induced by Gentamicin-Loaded Polymeric Multilayers on Magnesium Alloys." Colloids Surfaces B Biointerfaces 179: 429-36. 